\title{
WHEN ARE MARKETS ILLEGITIMATE?
}

\author{
BY AMANDA R. GREENE \\ Forthcoming in Social Philosophy and Policy
}

\begin{abstract}
In this essay I defend an alternative account of why markets are legitimate. I argue that markets have a raison d'être - a potential to be valuable that, if fulfilled, would justify their existence. I characterize this potential in terms of the goods that are promoted by the legal protection of economic agency: resource discretion, contribution esteem, wealth, diffusion of power, and freedom of association. I argue that market institutions deliver these goods without requiring the participants to have shared ends, or shared deliberation about joint ends-indeed, this feature is the source of the market's distinctive contribution to well-being. I suggest that when markets lack legitimacy, this is because they fail to fulfill their raison d'être, or fail to be recognized as doing so. Thus, the contours of legal protection must be drawn so that these goods are realized together in a recognizable way, without sacrificing one good for the sake of others. Finally, I argue that this account is appealing because it allows regulators to consider a plurality of goods, and because it makes room for the essential role of rhetoric in securing market legitimacy.
\end{abstract}

KEY WORDS: market, legitimacy, esteem, wealth, regulation, economic rights, economic justice

\section{INTRODUCTION}

Markets can fail to be legitimate. ${ }^{1}$ On this point, critics and defenders of the market agree. But they rarely see eye to eye about when and why a particular market is illegitimate. Sometimes this is because they have different accounts of why markets are a valuable form of social organization. Another reason is that it is difficult to establish whether a particular market is actually realizing those values. Yet another reason — and the one that concerns me here-is that it is unclear how the values that markets realize, whatever they may be, provide a basis for legitimacy.

What would it mean to say that a particular market is legitimate? This is a tough question, but at the very least, an assessment of legitimacy should tell us something that we do not know already. If verdicts of legitimacy are going to be informative, then they must be distinguished from two other kinds of evaluation: justice and legality. For instance, we may know that a market

\footnotetext{
${ }^{1}$ For helpful feedback and discussion, I would like to acknowledge Richard Arneson, Saba Bazargan, Daniel Callies, Rosalind Chaplin, Tom Christiano, David Estlund, Anca Gheaus, Aaron James, Niko Kolodny, Sara Mrsny, Ryan Muldoon, Tom Parr, Carmen Pavel, David Schmidtz, Gina Schouten, Seana Shiffrin, Lucas Stanczyk, Peter Vallentyne, Bas van der Vossen, Steve Wall, and David Wiens.
} 
is not fully just or morally ideal, but from this information alone, we cannot say whether it is illegitimate. If we go on to say that it is illegitimate, we are pointing to a distinct sort of failure in addition to a failure to be fully just. On the other hand, we may know that a market is legal, but from this information alone we cannot say whether it is legitimate. If we go on to say that it is legitimate, we imply that it meets a normative standard that goes beyond legal validity. The notion of legitimacy should help us identify which markets deserve legal protection, even if they are not fully just. ${ }^{2}$ We could do this if we had a way of diagnosing when a market fails to be legitimate. Imagine if we could say: a market is legitimate whenever it has properties $\mathrm{X}$ and $\mathrm{Y}$ because - in having these properties - it advances some value A to a suitable degree. Then we could ask of a particular market whether it has those properties, and on that basis, we could say whether it is legitimate. Such a standard would allow us to say that not all markets are legitimate, but some are.

At the moment we lack such a standard. And this has significant costs. For one thing, we lack a clear basis for criticizing markets that are falling short. As a consequence, those who are responsible for regulation lack guidance on what their aims should be-indeed, their very job description is unclear. Another cost is the polarization of public discourse on markets. On the one hand, radical critics of markets take any particular failure to show that markets should be viewed with suspicion. On the other hand, radical advocates of markets claim that apparent failures are illusions, since the market is working even if people cannot see it. The dominance of these extreme positions opens the door to a politics laced with mistrust and rhetorical manipulation.

If we had a clear standard for market legitimacy, however, we could identify when and where markets are failing. We could take steps to remedy those failures, even while falling short

\footnotetext{
${ }^{2}$ A standard of legitimacy should help with this question, but it is not equivalent to it.
} 
of justice. And, if the legitimacy standard were to draw on notions like utility, autonomy, and self-ownership, it would enable us to see exactly how and why those values contribute to the legitimacy of markets. This would allow us to attain a shared sense of the deeper human values that markets serve, as well as to make continuous improvements in their realization. That, in turn, would put us in a better position to collectively endorse the cultural practices that sustain markets.

In this essay I reconsider how the values that markets serve provide a basis for legitimacy. Several options have been proposed. Some theorists assume that the legitimating aim is efficiency (the utilitarian approach). Others assume that the legitimating aim is natural rights (the self-ownership approach). Still others see the legitimating aim as autonomy (the Kantian approach). Each of these approaches, I think, mistakes its part of the story for the whole. As an alternative, I propose that markets serve a plurality of goods. I hope to show how this plurality is tied together by a single unifying idea, which in turn provides a more comprehensive basis for the legitimacy of markets.

\section{A. Legitimacy as fulfillment}

Before turning to the market, I want to illustrate my approach to legitimacy with a simpler case: the public library. A library is an organized system for preserving and lending books, with characteristic patterns of cooperative behavior. What might be the point of such a system? How might it be valuable in light of human interests? It is natural to answer that it provides users with ready access to sources of knowledge, both now and in the future. Insofar as libraries are a potentially valuable form of social organization, we must make sense of their potential broadly in these terms. And it is natural to think that whenever a library fulfills its 
potential to be valuable in this way, such fulfillment would play a crucial role in justifying its existence. Thus we can think of public libraries as making an implicit claim about their reason for existing - their raison d'être.

It is possible for a library to fail in its core task of storing and lending books - say, for example, by renting out the building after-hours to raucous parties that eventually destroy the stock of books. It is possible for a library to fail at this even while doing a great deal of goodsay, by giving away all the books to the poor, or selling the books in order to raise money for cancer research. This illustration suggests that the raison d'être of a library marks out a special kind of failure, one that more fundamentally compromises its implicit claim to be a library. I suggest that this special kind of failure corresponds to legitimacy. In other words, a library gains legitimacy by achieving its raison d'être in such a way that the fulfillment is recognized by the relevant audience - the population in the town, county, or university to which it belongs. A library comes to be legitimate when its audience recognizes it as having fulfilled that implicit claim that would, if it were true, justify its existence. Conversely, a library lacks legitimacy when it fails to fulfill its raison d'être, or fails to be recognized as doing so. ${ }^{3}$ To speak at a more general level, my view is that items that can be deemed illegitimate present themselves as making a claim or promise, one that they may fail to fulfill or to be seen as fulfilling. ${ }^{4}$ When we are in the domain of social practices, we cannot evaluate their legitimacy without first identifying

\footnotetext{
${ }^{3}$ To be more precise, legitimacy consists of an objective element (fulfilling a promise to be valuable) and a subjective element (being seen as such by the relevant audience). For elaboration, see Amanda R. Greene, "The Logic of Legitimacy," unpublished manuscript.

${ }^{4}$ This way of understanding an implicit claim draws on an aspect of Joseph Raz's approach to normative concepts. He says, "There is a class of normative concepts that have a secondary use in which they indicate a claim by their users, or some of them, that they apply in their primary, normative, sense, a claim that may be erroneous . . ." (Joseph Raz, "The Problem of Authority: Revisiting the Service Conception," Minnesota Law Review 90 (2006): 1005-1006). While we share the idea of an implicit claim, Raz does not emphasize recognition in the way that I do.
} 
an implicit claim about their purpose, their raison d'être. In these cases, I suggest, legitimacy depends on recognition by participants that this claim has been fulfilled. ${ }^{5}$

In what follows I develop and defend a similar account of legitimacy for markets. I argue that when markets lack legitimacy, this is because they fail to fulfill their raison d'être, or fail to be recognized as doing so. But it is difficult to identify the raison d'être of markets. In the first part of the essay, I propose an account of the value potential of markets - their raison d'etre (Section II). In particular, I identify the goods that may be promoted by the protection of economic agency: these include resource discretion, contribution esteem, wealth, diffusion of power, and freedom of association. From this analysis, I extract the distinctive value potential of markets: the production of collective goods without collectivism. I argue that market exchanges do not require the participants to have shared ends, or shared deliberation about joint endsindeed, this feature is the source of their distinctive contribution to well-being (Section III). Finally, I argue that this account is appealing because it allows regulators to consider a plurality of goods, and because it makes room for the essential role of rhetoric in securing market legitimacy (Section IV). In closing, I offer some reflections on the moral significance of widespread acceptance of a valuable practice (Section V).

\section{THE PROMISE OF MARKETS}

Markets facilitate exchange. As Debra Satz says, "Markets are institutions in which exchanges take place between parties who voluntarily undertake them." ${ }^{6}$ At a merely descriptive

\footnotetext{
${ }^{5}$ To my mind, only some items in the world are suitable for the adjective "illegitimate," such as autographs, coins, and excuses. Items that are inapt for the adjective illegitimate include leaves, colors, and music. I suspect that apparent counterexamples rely on positing some social practices or expectations in the light of which these items could fail to be what they purport to be, for instance, music that is unfit for a funeral. As long as this is so, it supports rather than detracts from the analysis I defend in Amanda R. Greene, "The Logic of Legitimacy."

${ }^{6}$ Debra Satz, Why Some Things Should Not Be for Sale: The Moral Limits of Markets (New York: Oxford University Press, 2010), 15.
} 
level, we can say that a market is a complex of customary norms (social, cultural, and legal) that, taken together, allow for coordination and enforcement of the exchange of goods and services. Broadly speaking, markets promise to benefit all who take part in them. But they do this in a very particular way: by protecting, with the force of law, the organized exchange of goods and services. Thus markets promise to promote human interests through the customary protection of individual economic agency. This is the potential to be valuable that, if fulfilled, would justify the existence of the institution. I am not saying that markets always, or even usually, fulfill their promise. But insofar as markets are a potentially valuable form of social organization, we must make sense of their potential broadly in these terms.

What important human interests might be promoted or realized by the legal protection of exchange? Here I have in mind a scheme of legal rights related to economic agency, such as freedom of contract, entrepreneurial rights, and private property. I will be more specific later, but for now I will refer to these broadly as "economic rights." The question I want to ask is: What human interests might be served by recognizing and upholding these rights? ${ }^{7}$ By posing the question in this way, I am departing from a natural rights approach. According to an alternative approach based on interests, a right comes to be justified in virtue of some human interest (an aspect of well-being), provided that the interest is sufficiently important that others are held to have corresponding duties, ${ }^{8}$ and provided that the interest can be served or protected by the

\footnotetext{
${ }^{7}$ Attempts to justify markets can operate at different levels. Advocates can focus on the outcomes of exchange, the activity of exchange, the opportunity to exchange, or the legal protection of the opportunity to exchange. My focus is on the latter.

${ }^{8}$ Joseph Raz adopts the following definition: " $\mathrm{X}$ has a right if $\mathrm{X}$ can have rights, and, other things being equal, an aspect of X's well-being (his interest) is a sufficient reason for holding some other person(s) to be under a duty" (Joseph Raz, The Morality of Freedom [New York: Oxford University Press, 1986], 166). For Raz, the term "holding" is constructively ambiguous between judging that someone has a duty and imposing the duty on her (ibid., 171-72).
} 
duties. ${ }^{9}$ On the interest-based account, rights come to be justified ultimately in terms of their role in serving important human interests. ${ }^{10}$

In the case of economic rights, my proposal is that the legal protection of economic agency serves fundamental human interests by providing certain goods. These goods include two benefits at the individual level—namely, discretion over resources and social contribution esteem — and three benefits at the group level—namely, wealth, diffusion of power, and freedom of association. While these goods are plural, they form a nexus: the production of shared goods without shared ends. I propose that when a market fails to realize this nexus of human goods, or fails to be recognized as doing so, it lacks legitimacy.

\section{A. Individual good of resource discretion}

Economic rights can serve the interests of individual right-holders by providing resource discretion (examined in this section) and social contribution esteem (examined in the next section). ${ }^{11}$ We enjoy resource discretion when we have some control over our earning and spending. To take spending first, markets allow individuals to exercise considerable discretion over their consumption activities. With this discretion we can choose how we use our resources in accordance with our needs and wants, including making judgments about trade-offs.

\footnotetext{
${ }^{9}$ For Raz, a moral right qualifies for legal recognition only when it can be fairly and effectively protected through legal processes (Joseph Raz, "Human Rights Without Foundations," in The Philosophy of International Law, ed. John Tasioulas and Samantha Besson (Oxford: Oxford University Press, 2010), 321-38). According to Raz, the existence of any particular right depends on contingent facts about political institutions, although this dependence is not a form of relativism. See Joseph Raz, The Practice of Value (New York: Oxford University Press, 2003).

${ }^{10}$ According to Raz, "To assert that an individual has a right is to indicate . . that an aspect of his wellbeing is a ground for a duty on another person. The specific role of rights in practical thinking is, therefore, the grounding of duties in the interests of other beings" (Raz, Morality of Freedom, 180). Raz's conceptual framework has some features in common with the practice-based account outlined in G. E. M. Anscombe, "On the Source of the Authority of the State," Ratio 20, no. 1 (1978): 1-28.

${ }^{11}$ The discussion that follows builds upon ideas first outlined in Amanda R. Greene, "Making a Living: The Human Right to Livelihood," in Human Rights and Economic Liberties, ed. Bas van der Vossen and Jahel Queralt (Abingdon: Routledge, 2019), 155-63.
} 
Therefore, markets allow us to govern our spending in such a way that it partly reflects our idiosyncratic needs and desires.

To see this, consider someone whose food, housing, transportation, and health care are provided by the state. Like patients in a hospital, they are not able to exercise the most minimal agency over how their needs and wants are satisfied. Goethe offers this prophetic remark: "[With regard to] mankind's beautiful dream that things will go better someday ... I too am convinced that humanity will win in the end; my only fear is that at the same time the world will turn into a vast hospital and each of us will become his neighbor's sympathetic nurse." ${ }^{\prime 2}$ If all service provision is determined and delivered by the state, then we do not make individual choices about how to satisfy our wants and needs. Another way of seeing why this is important is to consider the virtue of generosity. When we lack control over how resources are used to satisfy our needs and desires, we cannot divert resources that would be spent on us toward others. For this reason, in fact, Aristotle argues that the collective ownership of resources hinders the exercise of temperance and generosity. ${ }^{13}$ At the very least, we are less able to give to others when we lack discretion over our resources.

Resource discretion is also enhanced when we have discretion over our earning. When we have some control over our productive activities, we have the power to intentionally act in ways that translate our time and talents into income. Granted, our income level is always partly

\footnotetext{
${ }^{12}$ The comment occurs in a letter to Charlotte von Stein, written during his travels in Italy in June 1787. See Johann Wolfgang von Goethe and Charlotte von Stein, Goethe's Briefe an Charlotte von Stein (Jena: E. Diederichs, 1908), 207. The translation is from Johann Wolfgang von Goethe, Letters from Goethe, trans. M. von Herzfeld and C. Melvil Sym (Edinburgh: Edinburgh University Press, 1957), 193. Nietzsche echoes the remark in a footnote in Friedrich Nietzsche, On the Genealogy of Morals and Ecce Homo (New York: Knopf Doubleday Publishing Group, 1989), 124.

${ }^{13}$ Aristotle says in the Politics, "It is very pleasant to help one's friends, guests, or companions, and do them favors, as one can if one has property of one's own. But those who ... [abolish] private property exclude these pleasures. They also [hinder] the virtues of temperance ... and generosity . . ., since one cannot show oneself to be generous, nor perform any generous action" ( $\mathrm{Pol} \mathrm{1263b5-11).} \mathrm{Here} \mathrm{and} \mathrm{throughout,} \mathrm{translations} \mathrm{are} \mathrm{from} \mathrm{Aristotle,}$ Politics, trans. C. D. C. Reeve (Indianapolis, IN: Hackett Publishing, 1997).
} 
determined by factors outside of our control. But we can calculate that this task or product has a price in our social context, and invest our time and energy in a way that leads to acquiring additional income. In other words, we can increase our resources according to the time and energy that we devote to income-generating activities. This means that our pool of discretionary resources is something we can deliberately and reflectively manage, at least to some degree. This ability to partly govern our resource situation is a significant contributor to well-being.

The discretion that I am talking about does not entail economic security or economic independence. In a complex economy, these things are as impossible as they are undesirable. What matters is that we are able to exercise some agency with regard to our various dependencies. ${ }^{14}$ One reason the affluent seek to maintain their wealth is that it puts them in a position to choose the mixture of economic dependencies that suits them. Therefore, resource discretion includes the ability to save, invest, and navigate financial risks, as these are valuable forms of second-order control. Having some control over the way in which one secures and manages resources is valuable over and above controlling the resources once they have been obtained.

When we have some control over our earning and spending, these two kinds of discretion work hand-in-hand to expand our sense of agency. When they are both present, we can intentionally manage how we translate our activity into needs-provision. This discretion allows us to meet our needs by a combination of active and passive means, in just the mix that suits us. Some of us want to have our own garden, some want a community garden, and some want to buy food from other people's gardens. In none of these cases do we escape dependence. It is just that a market provides a range of options, so that some negotiation of the boundaries of dependence remains in our hands. George Washington was fond of quoting the Hebrew Bible imagery of a

\footnotetext{
${ }^{14}$ Neither does this productive discretion necessarily imply a wide range of occupational options.
} 
paradise in which each family is dwelling beneath their own "vine and fig tree"—a longing that suggests that, while we can never be entirely independent, we still value having some control over how we meet our basic needs. ${ }^{15}$

The value of this discretion can be understood as an application of the principle of subsidiarity - roughly, the idea that it is better for decisions to be made at the lowest possible level of competence. If decisions have to be made about the terms of cooperation, then it is better for the cooperating parties to decide them than for some higher authority to do so. ${ }^{16}$ Since productive activity defines so much of our day-to-day experience, it is an important arena in which to be guided by our individual values and goals in life. For these reasons, resource discretion reflects important aspects of human well-being. ${ }^{17}$

\section{B. Individual good of social contribution esteem}

Markets offer us a unique way of being esteemed for our contributions: the sense of being valued that arises from uncoerced payment for work. When we participate in a market by selling our goods or our labor, we gain social contribution esteem. Granted, certain forms of unpaid

\footnotetext{
${ }^{15}$ The scriptural references to dwelling "under their own vine and fig tree" are identified and discussed in Daniel L. Dreisbach, "The 'Vine and Fig Tree' in George Washington's Letters: Reflections on a Biblical Motif in the Literature of the American Founding Era," Anglican and Episcopal History 76, no. 3 (2007): 299-326 and in Walter Brueggemann, “'Vine and Fig Tree': A Case Study in Imagination and Criticism," The Catholic Biblical Quarterly 43, no. 2 (1981): 188-204.

${ }^{16}$ As Stefan Gosepath explains, "In social and political philosophy the principle of subsidiarity is a principle which states that in the relationship among communities, but also in the relation of the individual to any form of human community, the smaller social or political entity or institution ought to be given priority (e.g., the individual should come before the community, the community before the state, the state before the federation, and so on). In this context, it is an important, if not the most important, responsibility of the bigger institution to enable the smaller one to perform its tasks and to provide it with any necessary support (subsidium) ... " (Stefan Gosepath, "The Principle of Subsidiarity," in Real World Justice: Grounds, Principles, Human Rights, and Social Institutions, ed. Andreas Føllesdal and Thomas Pogge, Studies in Global Justice [Dordrecht: Springer Netherlands, 2005], 15770). See also Andreas Føllesdal, "Survey Article: Subsidiarity," Journal of Political Philosophy 6, no. 2 (1998): $190-218$.

${ }^{17}$ For related discussion of the "goods of work," see Anca Gheaus and Lisa Herzog, "The Goods of Work (Other Than Money!)," Journal of Social Philosophy 47, no. 1 (2016): 70-89; Andrea Veltman, Meaningful Work (New York: Oxford University Press, 2016); Russell Muirhead, Just Work (Cambridge, MA: Harvard University Press, 2004).
} 
work are viewed as social contributions, but paid work offers a special kind of affirmation that our work is considered valuable by others in our community. This is because it involves an accumulation of many free individual decisions to spend money, a currency of universal value. Others are not under an obligation to buy our goods and services, nor are they forced to pay for them, so their free choice indicates their subjective valuation.

As Adam Smith observes, when we address ourselves to the self-interest of others, we put ourselves in a position to be recognized as someone who contributes something of value to them, by their lights. ${ }^{18}$ In a market, the price mechanism gives us comparative information about how to apply our time and talents, given our situated knowledge about our abilities and circumstances. We then use this information to engage in activity that others are likely to regard as valuable. Thus, the market allows us to experience being esteemed for our contributions, because we can observe how others value them through their willingness to pay. ${ }^{19}$ This lines up the fact of income with the recognition of the value of the product or service by those receiving it. Market-based income better achieves this alignment, because the determination of payment is closer to the perceived value of what is provided. ${ }^{20}$

There are ample reasons not to equate spending decisions with objective social value. ${ }^{21}$ However, spending decisions are a fair proxy for whether people believe something is valuable. They indicate the perceived value to others of what we do, thereby furnishing us with a basis for

\footnotetext{
${ }^{18}$ Adam Smith, An Inquiry Into the Nature and Causes of the Wealth of Nations, ed. W. B. Todd, vol. 1 (Indianapolis, IN: Liberty Fund, 1981 [1776]), 26-27.

${ }^{19}$ There are some kinds of labor where this does not hold, for instance, jobs pertaining to the administration of civil and criminal law. For an argument that such roles cannot be outsourced to a market, see Alon Harel, Why Law Matters (New York: Oxford University Press, 2014).

${ }^{20}$ For further defense of the importance of social contribution esteem, see Amanda R. Greene, "Making a Living," 156-58. There I argue that earned income in a market is an imperfect but decent indicator of beliefs on the part of others that our products and services are valuable, by their lights. The price mechanism is not a perfect instrument for conveying social contribution esteem; the point is that it can function this way in the right circumstances.

${ }^{21} \mathrm{~A}$ radical version of this sort of skepticism is the distinction between use value and exchange value outlined in Karl Marx, Capital: A Critique of Political Economy, vol. 1, trans. Ben Fowkes (New York: Vintage Books, 1977 [1887]).
} 
being valued by others as a contributor. It is important to observe that a buyer is not so much recognizing that we are valuable, but that something we have provided is valuable. This detaches the social worth judgment from the individual producers and transfers it onto their labor or products. Market-based income allows us to see our earnings as arising from the unforced recognition by others of the value of what we can provide, rather than having our income levels set by electoral politics, lobbying, or the government bureaucrat's incentives. ${ }^{22}$ Only then can the ensuing income be viewed as a signal of social contribution, and only then can it serve as a source of social contribution esteem. ${ }^{23}$

\section{Collective good of wealth}

So far I have been describing goods that are generated for individuals by the legal protection of their economic agency. Now I turn to the collective goods, those benefits that are provided more generally. ${ }^{24}$ Sometimes, rights come to be justified not only through serving the interests of the rights-holder, but through serving the interests of others. In other words, they bring about some social or cultural circumstances that are good for everyone, not just those who engage in the activity that is protected by the right. This logic can be found in J. S. Mill's argument that expressive liberties serve the collective interest in truth. ${ }^{25}$ Joseph Raz has expanded Mill's logic to cover a range of liberal rights:

\footnotetext{
${ }^{22}$ As I argue elsewhere, salaries for public employees reflect both the divergence between voters' evaluations and legislative decisions, and the divergence between legislative decisions and bureaucratic discretion. This puts considerable distance between the salary of teachers or transit workers and the perceived value of their contribution by wider society. Essentially, the gap is distorted by politics in ways that make it harder for workers to see their salary as reflecting their perceived social contribution (Amanda R. Greene, "Making a Living," 161-63).

${ }^{23}$ This account of contribution esteem has affinities with that of Tom Parr, "Automation, Taxation, and Unemployment," unpublished manuscript.

${ }^{24}$ Collective goods are not exactly equivalent to what economists call public goods, defined strictly as nonrival and non-excludable.

${ }^{25}$ John Stuart Mill, On Liberty, ed. Elizabeth Rapaport (Indianapolis, IN: Hackett Publishing, 1978 [1859]).
} 
[F]reedom of expression, privacy, freedom of religion, and the right against racial discrimination are examples [of rights] where one reason for affording special protection to individual interests is that thereby one also protects a collective good, an aspect of public culture ... [Thus liberal] rights protect collective goods and are assigned their special importance because they do so .... ${ }^{26}$

Thus, for Raz, liberal rights are justified by their contribution to well-being through the maintenance of a public culture. What might be the contribution of economic rights? My suggestion is that economic rights contribute to general well-being by providing three collective goods: wealth, diffusion of power, and freedom of association.

The first collective good that markets serve is wealth. Astute readers will have noticed that I did not mention wealth, or even utility, as an individual good served by markets. That is because I think it is more plausible to construe the utility gains that are produced by markets as a collective good: namely, the elevation of average real income. Markets achieve this because they lead to productivity gains and growth on a relatively sustainable basis. Markets are not the only means to this end, but they are a reliable and proven means of realizing it on a large scale. ${ }^{27}$ One plausible mechanism for this is the superior use of information in a market system. F. A. Hayek argues that markets solve two problems - the use of knowledge and the operation of incentivesthereby allowing for economic action that is better guided by the relevant information. He argues

\footnotetext{
${ }^{26}$ Raz, Morality of Freedom, 256-57 (emphasis added). Raz argues that freedom of contract, among other liberal rights, forms part of a healthy public culture (ibid., 252-53). He says, "[Earlier] it was suggested that the importance we attribute to the protection of those interests results from their service to the promotion and protection of a certain public culture. That culture is in turn valued for its contribution to the well-being of members of the community generally, and not only of the right-holders. The importance of liberal rights is in their service to the public good" (ibid., 256).

${ }^{27}$ Daniel M. Hausman and Michael S. McPherson, Economic Analysis, Moral Philosophy and Public Policy (New York: Cambridge University Press, 2006), 118-33; Satz, Why Some Things Should Not Be For Sale, 1721.
} 
that competition is a good procedure for discovering the most effective use of resources, because it induces many individuals to rationally and dynamically adjust to the actions of others. ${ }^{28}$

Another mechanism by which markets generate wealth is economic growth, facilitated largely by entrepreneurs and capitalists. Both bear financial risks privately: capitalists risk their own resources, while entrepreneurs are normally backed by investors. They both enable growth and increased productivity without the need for public assumption of risk. Entrepreneurship in particular is a vital source of endogenous economic growth, as Joseph Schumpeter points out. ${ }^{29}$ When entrepreneurship occurs on a regular and voluntary basis, it provides a durable basis for the steady increase of wealth.

When this sort of growth occurs consistently over time, the government can comfortably finance public goods through taxation. One of the most vital public goods is common defense, a precondition for the secure enjoyment of other goods. ${ }^{30}$ But tax revenue can also be used to fund goods like education, health care, dependent care, and the arts. Providing these further goods is possible only when there is an ample stream of tax revenue. When communities have spare resources to support these goods on a sustained basis, the whole group is better off. Some also argue that a community cannot fulfill its duties of care to members unless some people generate surplus wealth voluntarily. ${ }^{31}$

\footnotetext{
${ }^{28}$ F. A. Hayek, "The Use of Knowledge in Society," The American Economic Review 35, no. 4 (1945): 519-30. Hayek emphasizes that the benefits of competition do not "rest on the conditions that would exist if it were perfect" (F. A. Hayek, "The Meaning of Competition," in Individualism and Economic Order [Chicago: University of Chicago Press, 1948], 104). He says, "The real problem [addressed by competition] is how it can be brought about that as much of the available knowledge as possible is used ... [and] what institutional arrangements are necessary in order that the unknown persons who have knowledge specially suited to a particular task are most likely to be attracted to that task" (ibid., 95). See also F. A. Hayek, "Competition as a Discovery Procedure," trans. Marcellus S. Snow, The Quarterly Journal of Austrian Economics 5, no. 3 (2002): 9-23.

${ }^{29}$ Joseph A. Schumpeter, Capitalism, Socialism, and Democracy, 5th ed. (London: Allen and Unwin, 1976), 131-34.

${ }^{30}$ It can also be argued that preservation of the natural environment (e.g., clean air) is a necessary condition for the enjoyment of other goods and is therefore just as vital as defense.

${ }^{31}$ Francis Cheneval, "Entrepreneurial Rights as Basic Rights," in Van der Vossen and Queralt, eds., Human Rights and Economic Liberties.
} 
Besides unleashing the creation of wealth, markets also sustain wealth through the optimization of public spending. All markets require that some party—whether individual, group, or institution — play a governance function, and that party needs resources in order to operate effectively. Often this function is fulfilled by a state government, but not always; sometimes the common expenditure is managed through customary or voluntary arrangements. For simplicity, I will refer to the resources required for upholding the market as "public expenditure." Markets provide incentives to keep public expenditure efficient—-that is, as low as possible while still enabling exchange to occur. When a market is functioning well, the resources that are required for governance are collected from all participants. In this arrangement, the pool out of which public expenditures are funded is perceived by contributors as a sum of privatelygenerated wealth. In a state, this means that the government relies mostly on taxation for its income. Individuals perceive the taxes they pay the government as given, not merely returned. ${ }^{32}$ Hence it is felt that the government depends on the people, rather than the other way around. This leads to a sense of ownership and accountability regarding common expenditure: not only is money spent in the name of all those involved, the money that is spent is regarded as the people's money.

This sense of ownership, in turn, has positive effects on the quality of public spending. Here I draw on an argument advanced by J. S. Mill:

Those who pay no taxes, disposing by their votes of other people's money, have every motive to be lavish, and none to economize. [This produces] . . . a severance of the power of control, from the interest in its beneficial exercise. It amounts to allowing them to put their hands into other people's pockets, for any purpose which they think fit to call a

\footnotetext{
${ }^{32}$ I deliberately say "perceive" to highlight that questions of ownership rights are not settled prior to and independent of the scheme of taxation. See Liam Murphy and Thomas Nagel, The Myth of Ownership: Taxes and Justice (New York: Oxford University Press, 2002).
} 
public one; which in some of the great towns of the United States is known to have produced a scale of local taxation onerous beyond example, and wholly borne by the wealthier classes .... It is essential, as it is on many other accounts desirable, that taxation, in a visible shape, should descend to the poorest class. ${ }^{33}$

When those with the power to spend public funds are accountable to those paying into the treasury, this maintains the link, as Mill says, between "the power of control" (raising and spending common funds) and "the interest in its beneficial exercise." Moreover, Mill thinks that this tax burden should be felt by everyone directly, in a way that is unmediated by consumption: In this country, and in most others, there is probably no labouring family which does not contribute to the indirect taxes, by the purchase of tea, coffee, sugar, not to mention narcotics or stimulants. But this mode of defraying a share of the public expenses is hardly felt: the payer, unless a person of education and reflection, does not identify his interest with a low scale of public expenditure, as closely as when money for its support is demanded directly from himself; and even supposing him to do so, he would doubtless take care that, however lavish an expenditure he might, by his vote, assist in imposing upon the government, it should not be defrayed by any additional taxes on the articles which he himself consumes. It would be better that a direct tax, in the simple form of a capitation, should be levied on every grown person in the community ... so every one might feel that the money which he assisted in voting was partly his own, and that he was interested in keeping down its amount. ${ }^{34}$

\footnotetext{
${ }^{33}$ John Stuart Mill, The Collected Works of John Stuart Mill, ed. John M. Robson, vol. XIX, Part 2 (Toronto: University of Toronto Press, 1977 [1861]), 471.

${ }^{34}$ Shortly thereafter Mill argues that the destitute have no claim to influence public spending, a claim that I neither endorse nor need to endorse, since my argument relies on the operation of incentives at a general level (Mill, The Collected Works of John Stuart Mill, 471-72).
} 
I read Mill as making an argument here about the operation of incentives: when we feel that our contribution to the public expenditure comes out of our own private wealth, we are keen to keep the expenditure low and ensure that it serves our interests. In other words, we are incentivized to make sure that the costs of governance are worthwhile and not overly burdensome.

Mill's argument is echoed in debates about development aid. Dambiso Moyo argues in Dead Aid that as long as governments derive substantial portions of their budgets from foreign donors, they do not need tax revenue from their citizens. Speaking from her own experience in sub-Saharan Africa, she suggests that a lack of reliance on the private wealth of citizens reduces the degree to which governments feel — and actually are — accountable to their citizens. She argues that foreign aid reduces the government's financial dependence on its citizens, which in turn, reduces accountability. This can lead to a system in which the citizens are economically reliant on the government, rather than the other way around. ${ }^{35}$

These observations indicate that when a market is functioning well, its system of public spending will be optimized to serve wealth creation, since its operating revenue depends on taxation of this wealth. Leaders have an incentive to make sure that the common expenditure is effective and efficient, and that it is seen as such. They are also motivated to ensure that the collective public expenditure does not have unintended consequences that would impede the production of wealth. These dynamics provide an incentive for prudent public spending, which in turn allows wealth to be sustained and increased over time.

\footnotetext{
${ }^{35}$ It should be acknowledged that development is complex, and it is difficult to isolate any single factor as determinative across a variety of contexts. Still, Moyo offers a reasoned defense: "In most functioning and healthy economies, the middle class pays taxes in return for government accountability. Foreign aid short-circuits this link . . . In an aid environment, governments are less interested in fostering entrepreneurs and the development of their middle class than in furthering their own financial interests. Without a strong economic voice a middle class is powerless to take its government to task. With easy access to cash a government remains all-powerful, accountable only (and only then nominally) to its aid donors . . . Because the government's financial dependence on its citizens has been reduced, it owes its people nothing" (Dambisa Moyo, Dead Aid [New York: Macmillan, 2009], 57-58).
} 


\section{Collective good of diffusion of power}

Another collective good that markets promote is the diffusion of power. When markets are functioning properly, they allow us to avoid systematic dependence on a few powerful actors, whether those actors be public or private. Someone may worry that markets facilitate the domination of the many by the few. ${ }^{36}$ It is true that markets cannot eliminate the dependence of some individuals on other individuals who have more power. But markets are a necessary part of avoiding large-scale and systematic dependence of many people on a small number of actors. ${ }^{37}$

Without market freedoms, there is a risk that two spheres of power will converge, thus amplifying the concentration in each. Michael Walzer argues that by maintaining a separation between the spheres of economics and politics, we can avoid having differential economic power translate into differential political power. ${ }^{38}$ Milton Friedman goes further, suggesting that separating economic and political power counteracts the tendency of power to become more and more concentrated:

[C]ompetitive capitalism ... separates economic power from political power and in this way enables the one to offset the other... The fundamental threat to freedom is the power to coerce, be it in the hands of a monarch, a dictator, and oligarchy, or a momentary majority. The preservation of freedom requires the elimination of such

${ }^{36}$ Despite the celebrity of Thomas Piketty's work on capitalism and inequality, the historical record does not settle the question (Thomas Piketty and Arthur Goldhammer, Capital in the Twenty-First Century [Cambridge MA: Harvard University Press, 2014]; David N. Weil, "Capital and Wealth in the Twenty-First Century," American Economic Review 105, no. 5 [2015]: 34-37; J. E. King, “The Literature on Piketty," Review of Political Economy 29, no. 1 [2017]: 1-17). A historian looking across centuries argues that the only mechanisms that are known to reduce inequality are wars and pandemics (Walter Scheidel, The Great Leveler: Violence and the History of Inequality from the Stone Age to the Twenty-First Century [Princeton, NJ: Princeton University Press, 2017]).

${ }^{37}$ Someone may still think that economic concentrations of power are more threatening than political ones, but this is usually because they are thought to conflict with norms of equality See Elizabeth Anderson, Private Government (Princeton, NJ: Princeton University Press, 2017).

${ }^{38}$ Michael Walzer, Spheres of Justice: A Defense of Pluralism and Equality (New York: Basic Books, 1983). 
concentration of power to the fullest possible extent and the dispersal and distribution of whatever power cannot be eliminated ... By removing the organization of economic activity from the control of political authority, the market eliminates this source of coercive power. It enables economic strength to be a check to political power rather than a reinforcement ... ${ }^{39}$

Friedman's point here is not that economic power will always counterbalance political power. Rather, it is that economic power has a chance of doing so only if it is kept separate from political power. This observation implies that, when markets are functioning properly, they provide a means of counteracting the concentration of political power, thereby promoting the overall diffusion of power. In order for a market to deliver on this promised good, it must be organized in such a way that it prevents monopolies, lowers barriers to entry, and avoids elite capture of regulatory power.

\section{E. Collective good of freedom of association}

Another collective good that markets provide is a public culture of freedom of association - that is, a rich and varied civil society that is characterized by the easy and regular formation of associations for all kinds of purposes. A shared social practice that allows us to step in and out of these associational ties without seeking the permission of an authority is valuable. ${ }^{40}$

${ }^{39}$ Milton Friedman and Rose D. Friedman, Capitalism and Freedom (Chicago: University of Chicago Press, 1962), 9, 15-16. He goes on to say, "There seems to be something like a fixed total of political power to be distributed. Consequently, if economic power is joined to political power, concentration seems almost inevitable. On the other hand, if economic power is kept in separate hands from political power, it can serve as a check and a counter to political power" (ibid., 16).

${ }^{40}$ The freedom to associate implies a freedom not to associate. In certain social circumstances, this can have important negative consequences that should be monitored and, if need be, addressed. See Nancy Rosenblum, Membership and Morals: The Personal Uses of Pluralism in America (Princeton, NJ: Princeton University Press, 
This value is most visibly embodied in the political culture of the United States, but its theoretical defense derives from European theorists of liberal democracy such as J. S. Mill and Alexis de Tocqueville. For instance, Tocqueville hails freedom of economic association as an essential part of a healthy political culture. In Democracy in America he says, [American] citizens think constantly of using the right of association in civil life and thus have managed to enjoy all the benefits which civilization offers ... By chance men share an interest in a certain matter; maybe the management of a commercial enterprise or the conclusion of an industrial operation; they meet and join together, gradually familiarizing themselves thus with the idea of association. The more the number of these minor communal matters increases, the more men acquire, even unknowingly, the capacity to pursue major ones in common ... Civil associations, therefore, pave the way for political associations ... ${ }^{41}$

Thus, Tocqueville sees economic associations as important training grounds for political cooperation. But more significantly, he argues that this benefit will be reaped only if there is legal protection of the right of association:

When citizens can combine [through associating] only in certain restricted cases, they look upon associations as a rare and peculiar occurrence and scarcely give any thought to them. [On the other hand,] when they have the freedom to combine for all purposes, they end up seeing associations as the universal and, as it were, the unique means for men to attain their various aims ... Thus the skill of association becomes, as I have said before, the root of all skills ... [But] when certain associations are prohibited and others allowed,

1998); Kathleen M. Sullivan, "The New Religion and the Constitution," Harvard Law Review 116, no. 5 (2003): 1397-1421.

${ }^{41}$ Alexis de Tocqueville, Democracy in America: And Two Essays on America (London: Penguin Books Limited, 2003 [1835]), 604-605. 
it is difficult to tell in advance the difference between the former and the latter. Doubt persuades people to steer clear of both and, in a vague, way, public opinion tends to consider any association at all as a rash and almost illegal enterprise $\ldots{ }^{42}$

Tocqueville argues that it is the right to associate, as much as the activity itself, that benefits the public. Where only some associations are allowed, there is enough doubt to discourage the practice in general, thereby harming the public culture. Here he is not resting his defense on the outcomes of association, or even the activity of association — rather, his defense rests on the salutory effects of wide legal protection of association. Hence, Tocqueville thinks that what is essential to a healthy public culture is the absence of restrictions on associational life, including economic associations. Tocqueville's argument resonates with liberal perfectionists ranging from Mill to Raz, who argue that the legal protection of individual rights promotes important collective goods for society.

\section{COOPERATION Without COLLeCTIVISM}

So far I have defined markets as a mode of human association that protects economic agency through legal and cultural norms. I have proposed that this protection has the potential to promote a range of individual and collective goods. Now I want to bring together the various goods that I have outlined, and point to an underlying theme that unifies them: the production of collective goods without the requirement of collectivism. Collectivism demands that we affirm an outlook that puts the group's aims ahead of individual pursuits. No doubt some amount of trust and fellow-feeling is necessary for cooperation over time, but collectivism demands more. It requires that individuals cast their lots in together, avowing a commitment to privileging

\footnotetext{
${ }^{42}$ Ibid., 606-608.
} 
whatever the common good requires when they are deciding and acting together. This sort of collectivism demands that all productive activity be oriented above all to the good of the whole. Markets, in contrast, allow for the pursuit of a diverse and potentially conflicting array of private aims, without requiring coherence at the level of a group aim. To illuminate this point further, I turn to Aristotle.

\section{A. Economic and political association}

Aristotle famously describes human beings as political animals. ${ }^{43}$ But what marks out a political community from other types of social organization, for Aristotle? Often we focus on Aristotle's conclusion that a city is, essentially, a partnership in virtue. ${ }^{44}$ But it is instructive to look again at the starting point of the investigation. Aristotle begins by defining the political community as that which is self-sufficient for living well. ${ }^{45}$ But why not, then, count as political other forms of community that are big and diverse enough to adequately provide for the common welfare—-such as, for example, a marketplace?

Aristotle sees the force of this objection, since he straightaway considers communities based on exchange:

" ... [Consider] that people do not [come together as a community merely] for the sake of an alliance to safeguard themselves from being wronged by anyone, nor to facilitate exchange and mutual assistance, since otherwise the Etruscans and Carthaginians, and all those who have treaties with one another would virtually be citizens of one city-state. To

\footnotetext{
${ }^{43}$ For further discussion and comparison of the places in which Aristotle relies on this idea, see John M. Cooper, "Political Animals and Civic Friendship," in Aristotle's Politics: Critical Essays, ed. Richard Kraut and Steven Skultety (Lanham, MD: Rowman and Littlefield, 2005), 65-89.

${ }^{44}$ The term aretē can also be translated as excellence (and perhaps should be, to avoid the Christian connotations of virtue).

${ }^{45}$ Aristotle, Politics, 1252 b28.
} 
be sure, they have import agreements, treaties about refraining from injustice, and formal documents of alliance, but no offices common to all of them have been established to deal with these matters; instead each city-state has different ones. Nor are those in one city-state concerned with what sort of people the others should be, or that none of those covered by the agreements should be unjust or vicious in any way, but only that neither city-state acts unjustly toward the other ... ${ }^{46}$

One might be inclined to hear these remarks as a Hobbesian observation that the enforcement of contracts is necessary for justice. But that would miss the deeper point. These treaty agreements are about cooperative arrangements for mutual advantage, and the terms include enforcement. Since these agreements are not enough to constitute a political community, according to Aristotle, the political community must be more than just a system of cooperation with an agreed mechanism of enforcement. Aristotle emphasizes this further by explicitly considering the case of a stable and complex market:

... If there were some who lived separately, yet not so separately as to share nothing in common, and had laws against wronging one another in their business transactions (for example, if one were a carpenter, another a farmer, another a cobbler, another something else of that sort, and their number were ten thousand), and they shared nothing else in common besides such things as exchange and alliance — not even in this case would there be a city-state. What, then, is the reason for this? Surely it is not because of the nonproximate nature of their community. For suppose they joined together while continuing to share in that way, but each nevertheless treated his own household like a city-state, and the others like a defensive alliance formed to provide aid against wrongdoers only. Even

\footnotetext{
${ }^{46}$ Ibid., 1280a34-1280b4.
} 
then this still would not be thought a city-state by those who make a precise study of such things, if indeed they continued to associate with one another in the same manner when together as when separated. ${ }^{47}$

For Aristotle, it is quite possible to imagine large-scale communities that are sufficiently organized and self-sustaining to provide for the needs of their members through trade. He is effectively describing a marketplace, right down to the division of labor. In these circumstances, the participants have no shared end beyond perpetuating a system of mutual advantage, where advantage is to be judged privately by the parties to the cooperation.

Such a marketplace does not count as the highest form of human community, for Aristotle, because the individuals are not partners in deliberative choice- that is, they do not choose together to live together:

Evidently, then, a city-state is not a sharing of a common location, and does not exist for the purpose of preventing mutual wrongdoing and exchanging goods. Rather, [a city-state exists] only when households and families live well as a community whose end is a complete and self-sufficient life. ... [This] is the result of friendship, since the deliberative choice of living together constitutes friendship. ${ }^{48}$

Aristotle claims, then, that participants in a market are not truly partners in deliberative choice. Otherwise they would "establish offices in common" to deal with any matters that arise. This system of common offices would have to go beyond the enforcement of contracts, since Aristotle thinks such enforcement is available in relations based on trade and defense. For Aristotle, contract enforcement exists only for the sake of "preventing wrongdoing and exchanging goods."

\footnotetext{
${ }^{47}$ Ibid., 1280b17-28.

${ }^{48}$ Ibid., 1280b29-38.
} 
In contrast, when the parties to the association "establish offices in common," this evinces a commitment to be partners in the exercise of deliberative choice.

Here is the key point for my argument. On this reading of Aristotle, it is characteristic of trade relations that they do not involve a partnership in choosing ends, including shared deliberation about the means to those ends. Otherwise trading relations would not be different enough from membership in a political community. Aristotle speaks of alliances for trade and defense as falling short of a political community because they do not involve the sharing of ends, or even sharing in deliberation about joint ends. Because they lack this feature, according to Aristotle, these sorts of relations fall short of the highest form of human community.

What Aristotle sees as the crucial defect of a marketplace can, instead, be seen as a strength. In a market, individual parties pursue their separate ends, and their cooperation is merely a means. A system in which participants exchange goods and services for the sake of mutual advantage does not require a sharing of ends. Some instances of market exchange may involve shared ends incidentally, but this is extraneous. Nor does exchange require any kind of co-deliberation of how best to pursue joint ends. What might appear to be deliberation about the terms of the exchange is effectively a bargaining process. Individual parties deliberate for themselves about the terms on which they are willing to go ahead, and then reveal that to other parties in whatever way best serves their interests. Therefore, market exchange is instrumental in nature - it is a means to ends that the parties have chosen separately and independently of that particular exchange.

\section{B. Collective goods without collectivism}


Drawing on this element of Aristotle's analysis, I suggest that the distinctive feature of markets, as compared to other forms of social organization, is that they facilitate cooperation without shared aims. A market system facilitates beneficial cooperation by assigning some legal protection to economic agency, while neither neglecting nor overstating its significance. When a system allows individuals to pursue their own ends, and at the same time, to generate mutual advantage with others who do not share their ends, then its participants get some benefits that they would not get otherwise. This potential is unique to markets.

This way of understanding the unique potential of markets resonates with F. A. Hayek's defense of the market. Like Aristotle, he thinks it is characteristic of a market not to be oriented toward a uniform hierarchy of ends. Thus, Hayek distinguishes between economy and catallaxy: an economy is an organization in which "all effort is directed toward a uniform order of objectives" (such as a household or a business), whereas catallaxy refers to spontaneous order. He argues that what we currently call "the economy" is actually order that emerges spontaneously from patterns of exchange, and that "the objectives it serves are actually the particular objectives of all its participants in all their diversity and polarity." ${ }^{49}$ Hayek thinks that this feature is the distinctive advantage of market forms of social organization. It is important to acknowledge that the parties to an exchange may in fact be motivated to bring about mutual benefit, and that the practice of exchange may engender virtuous dispositions over time. ${ }^{50}$ However, such motivations and dispositions are not essential for the market to deliver the benefits of cooperation on a large scale. ${ }^{51}$

\footnotetext{
${ }^{49}$ Hayek, "Competition as a Discovery Procedure," 14.

${ }^{50}$ For an exploration of the aim of mutual advantage as characteristic of markets, see Robert Sugden, The Community of Advantage: A Behavioural Economist's Defence of the Market (New York: Oxford University Press, 2018). For an argument that market society promotes bourgeois virtues, see Deirdre N. McCloskey, The Bourgeois Virtues: Ethics for an Age of Commerce (Chicago: University of Chicago Press, 2006).

${ }^{51}$ Max Weber, like Aristotle, also explicitly characterized a political community in terms of a values-based social ordering that goes beyond mere economic cooperation. See Ilaria Cozzaglio and Amanda R. Greene, "Can
} 


\section{Legitimacy of markets}

Now we can return to the question of legitimacy. At the most general level, markets promise to benefit those who participate in them through the protection of a sphere of economic agency. The unique potential of markets, I have suggested, is to enable the sort of beneficial cooperation in which participants need not share ends. This is its raison d'être, I submit. And just as with the public library, insofar as a market does not fulfill its raison d'être, or it fails to do so in a way that is recognized by participants, it lacks legitimacy.

In the discussion of the goods served by markets, I spoke of "markets functioning properly." This idea of proper functioning allows me to be more precise about the economic rights that are suitable for realizing this raison d'être. In order to provide resource discretion, a market must minimize interference in freedom of contract—-for instance, licensing schemes. ${ }^{52}$ Discretion over consumption requires avoiding a welfare system so extensive that virtually all consumption decisions are made by the state. In order for a market to function in such a way that it delivers the collective good of wealth, there must be a strong presumption against price controls and wage controls. The interest in promoting wealth through optimal public expenditure implies that the tax base should be broad, so that the burden is not thrust chiefly on the poor or the wealthy, and so that public spending is directed toward public goods. The interest in diffusion of power implies the fostering of a competitive environment, including effective mechanisms to prevent monopolistic behavior and elite capture of regulatory agencies. While

Power Be Self-Legitimating? Political Realism in Hobbes, Weber, and Williams," European Journal of Philosophy (2019); Amanda R. Greene, "Legitimacy without Liberalism: A Defense of Max Weber's Standard of Political Legitimacy," Analyse and Kritik 39, no. 2 (2017): 295-324; Max Weber, Economy and Society: An Outline of Interpretive Sociology (Berkeley: University of California Press, 1978).

${ }^{52}$ By this I mean mandatory licensing only. Freedom of contract is not hampered in the same way by voluntary licensing schemes, such as those offered by professional associations and insurance providers. 
this is not the place for an exhaustive list, these are the sorts of features of a market that would allow it to function properly - that is, to achieve its raison d'être. Whether all of these features can be suitably combined is a question I will address below.

It is worth clarifying why this standard of legitimacy is a moral standard, even though it is distinct from justice. First, the raison d'être is something that has pro tanto moral value because it corresponds to important human interests - for instance, resource discretion. Resource discretion is morally significant even when it is imperfectly realized and contingent on certain background conditions. Therefore, a legitimacy standard that requires the fulfillment of this raison d'être incorporates an aspect of morality. The second way in which the standard is moral is more subtle because it pertains to beliefs. Someone might be inclined to think of criteria that rely on social facts about a practice, such as the beliefs of those involved in the practice, as merely sociological — that is, belonging on the descriptive side of the normative-descriptive divide. However, I think this is too quick. When participants in a practice recognize that a practice has value and accept it on that basis, such widespread acceptance takes on moral significance. In these circumstances, participants come to engage with social structures in a nonalienated way and, over time, learn to pursue their interests in ways that align with the perceived interests of others. This mode of engagement is often the critical ingredient in cooperative social orders whose maintenance does not rely on oppressive coercion. While some participants may have mistaken beliefs, this does not necessarily cancel out the value of their non-alienated participation in a practice that has moral value. For these reasons, the standard of legitimacy I am proposing can be seen as one register of moral evaluation, though it is distinct from other aspects of morality such as justice and welfare-promotion. ${ }^{53}$

\footnotetext{
${ }^{53}$ For further defense of this recognition-oriented account of legitimacy, see Amanda R. Greene, "Is Political Legitimacy Worth Promoting?", NOMOS: Journal of the American Society for Political and Legal
} 


\section{What market legitimacy is not}

The account I defend implies that some common criticisms of markets, if true, would not make them illegitimate. For example, it is sometimes said that markets embody a kind of justice, one that is based at least partly on responsibility. According to these views, the divergence between actual outcomes and the outcomes that we are responsible for is a problematic aspect of markets - one that calls their legitimacy into question. We could close that legitimacy gap, they say, by altering market outcomes in such a way that they better track responsibility. ${ }^{54}$ But notions of responsibility are at least partly internal to the institutional framework of markets. ${ }^{55}$ To my mind, this suggests that tracking a market-independent notion of responsibility cannot be what a market is for, fundamentally speaking, and thus cannot be what grounds its legitimacy.

Others argue that markets embody a kind of justice that is based at least partly on equality, taking this to be the legitimating aim of markets. Whether this is plausible depends on what is meant by equality. Equality of outcomes, to take one interpretation, is evidently incompatible with the definition of a market, since a crucial element is competition for unequal shares. Equality of opportunity, another interpretation, also seems to be in tension with the basic definition of a market, at least insofar as that includes an ordinary understanding of private

Philosophy LXI (2019): 65-101. For an alternative standard of legitimacy that features recognition, see Allen Buchanan, "Institutional Legitimacy," Oxford Studies in Political Philosophy 4 (2018): 53.

${ }^{54}$ Theorists of distributive justice carefully develop moral distinctions that would justify interfering in some market outcomes and not others - such as between choice and circumstance, or between "brute luck" and "option luck" (Zofia Stemplowska and Carl Knight, eds., Responsibility and Distributive Justice [New York: Oxford University Press, 2011], 7-10). Seminal versions of responsibility-oriented theories include Richard J. Arneson, 'Equality and Equal Opportunity for Welfare', Philosophical Studies 56, no. 1 (1 May 1989): 77-93; G. A. Cohen, 'On the Currency of Egalitarian Justice', Ethics 99, no. 4 (1 July 1989): 906-44; and Ronald Dworkin, 'What Is Equality? Part 2: Equality of Resources', Philosophy \& Public Affairs 10, no. 4 (1981): 283-345.

${ }^{55}$ For an argument that responsibility is not independent of market relations, see Susan Hurley, "The Public Ecology of Responsibility," in Responsibility and Distributive Justice, ed. Stemplowska and Knight, 187-215. This is also true of notions of desert: while it is possible to develop a notion of "institutional desert," its relationship to natural or moral desert is not straightforward. See Lisa Herzog, "Can Incomes in Financial Markets Be Deserved? A Justice-Based Critique," in Just Financial Markets? Finance in a Just Society (New York: Oxford University Press, 2017(, 103-23. 
property as inheritable. ${ }^{56}$ A third option is equal concern for persons, a view that requires the government to remedy some inequalities brought about by markets through a fair scheme of taxation, where this is defined by what citizens would endorse from a hypothetical perspective. ${ }^{57}$ Locating the legitimacy of markets in a hypothetical choice situation relies on a notion of fairness that is at odds with the essential features of markets, in my view. All actual exchange is the result of bargaining under conditions of asymmetric information and power, and the exploitation of this positional knowledge is precisely what enables markets to deliver their distinct benefits. To my mind, this opposition between equality and the essential dynamics of markets indicates that equality cannot be what a market is for, fundamentally speaking, and thus cannot be what grounds its legitimacy. ${ }^{58}$

Failures to realize equality or track responsibility would not compromise market legitimacy, in my view. While they may be desirable or good-making features of a market or a society, their absence does not — in and of itself — make a market illegitimate. To see this, consider the library example again. There are ways in which a public library could fall short on these dimensions but not be illegitimate. The library may waive fines twice as often for those who bring doughnuts to the librarian (unequal concern), or impose fines without due regard for whether the user had a good reason (insensitive to responsibility). It can be true that the library

\footnotetext{
${ }^{56}$ For an argument against strong rights of inheritance, see Daniel Halliday, Inheritance of Wealth: Justice, Equality, and the Right to Bequeath (Oxford, New York: Oxford University Press, 2018).

${ }^{57}$ See Ronald Dworkin, Sovereign Virtue: The Theory and Practice of Equality (Cambridge, MA: Harvard University Press, 2000); John Rawls, A Theory of Justice (Cambridge, MA: Belknap Press, 1971). Especially in his later work, Dworkin suggests a view of economic rights in which equality and responsibility form part of a multifaceted, interpretive ideal of justice. While I lack space to discuss it properly, there are some parallels with an account of market legitimacy based on a nexus of goods.

${ }^{58}$ Some find current labor markets to be illegitimate simply because of the power asymmetries between employers and employees (Anderson, Private Government). As Niko Kolodny points out, it is difficult to say exactly when and why those power asymmetries are objectionable. See Niko Kolodny, "Help Wanted: Subordinates," in Private Government, 99-107.
} 
would be better if it avoided these things, but that fact by itself does not show that the library is illegitimate.

Ultimately, these ways of criticizing particular markets rest on judgments about justice. Why should we expect markets to be fully just in order to be legitimate? Some of the criticisms boil down to second-order claims about an overlapping consensus on justice (say, one that can be endorsed by all reasonable people). But again, why should we expect markets to reflect shared judgments about justice in order to be legitimate? As Aristotle points out, the commitment to common adjudication of questions of justice is distinctive of a political community, not an economic one. What markets offer, instead, is a form of social order that functions without shared views of justice. Therefore, my disagreement with those who theorize about the justice of markets goes deeper than the intramural debates about egalitarianism and distributive fairness. The standard of legitimacy that I defend leaves open the possibility that markets make their distinctive contribution to human welfare - and thus warrant our endorsement - without necessarily claiming to advance equality or distributive justice.

\section{ACHIEVING LeGitimate MARKETS}

How is legitimacy to be achieved for any particular market? Everything depends on crafting and calibrating the boundaries of protected economic activity. Again, it is helpful to think of this calibration in terms of "proper functioning." A market is functioning properly when its legal protections of economic agency enable the simultaneous and stable realization of the nexus of human goods that markets promise to deliver. Determining the legal protections and constraints that apply to exercises of economic agency is the task of regulators, who must 
balance the plurality of goods that markets aim to realize. Achieving this balance is difficult but by no means impossible, a point that I want to illustrate with two analogies.

\section{A. Regulation as balancing and blending}

Suppose that I am drafting an essay prompt for a university course on Rousseau. I am aware that one student has read Rousseau before and is particularly gifted at philosophy, and I want the essay prompt to be challenging for her. But I am also aware that many students, probably the majority, are not capable of grappling with the deepest elements in Rousseau's thought before the deadline. Therefore, I should construct a prompt that will be engaging both to the majority and to the star student. Furthermore, I want to balance two modes in which the essay assignment serves their interests. One mode pertains to the outcome: excellent essays. Another mode pertains to the process of reckoning with the material. The prompt should be challenging enough that students learn something in the process of attempting to answer it. The gains of this reckoning are distinct from whether the resulting output is a superb essay (sometimes it turns out worse). As an instructor, I seek to balance these two aims rather than neglect one for the sake of the other.

To take another example, suppose that I am planning the menu for a feast in which a large family cooks and eats together. I should choose dishes that are both engaging to make and pleasurable to eat, thereby balancing outcome goods (tasty food) with process goods (enjoyable cooperation in cooking). Also, I should select an array of dishes that are hated by no one (or offlimits due to dietary restrictions), thereby balancing individual and group satisfaction. My fourpart balancing act must also accommodate the physical constraints of time and equipment. 
Anyone who has ever planned the menu for a feast or drafted an essay question will recognize that balancing these different goals is difficult but not impossible. The fact that the goods are plural and occur in different modes makes balancing them a more complex task, one that is not reducible to a maximizing calculus. Still, there is a kind of excellence involved in devising a single coordination mechanism for a non-uniform group, in such a way that the group jointly realizes a range of goods. In the best-case scenario, the goods are not just balanced, but blended, and even integrated. Crafting regulations for a market involves a similar sort of balancing.

\section{B. Regulating markets}

I have proposed that markets have the potential to realize a nexus of human goods through the protection of economic agency. In order to determine the appropriate contours of this protection, regulators must consider how to balance and blend these goods in such a way that they can be jointly realized. When this realization is achieved in a given set of circumstances, a market is functioning properly. This way of thinking reminds us that there is no market without some regulation, thereby avoiding the false naturalization of economic relations.

Economic agency can be regulated in ways that not only fail to realize these goods, but actually set them back. For example, the regulatory framework for collateralized debt leading up to the 2008 American mortgage crisis led to a situation in which several goods that should have been advanced by the market were set back, to say the least. Therefore, regulators can fail in their balancing act through inadequate calibration. This inadequate calibration could manifest itself in several different ways - for instance, loss of individual discretion over consumption, or 
an excessive concentration of power in a few hands. When this happens, it suggests that the delicate calibration of laws pertaining to economic agency needs to be revisited and adjusted.

To guard against this sort of calibration failure, regulators should never entirely sacrifice one element in the nexus of values for the sake of maximizing another element. Such an unbalanced approach is often the result of the influence of particular schools of political thought. Some approaches to regulation (often associated with economics) are tempted to sacrifice freedom of association for the sake of maximizing utility. Other approaches (often associated with social democrats) are tempted to sacrifice utility in order to promote social esteem. And other approaches (often associated with libertarians) are tempted to sacrifice the diffusion of power for the sake of resource discretion. They all grasp part of the truth about market legitimacy, in my view, but mistake their part for the whole.

The goal of regulation, on the account of market legitimacy I have been defending, is to (i) uphold the proper functioning of the market and (ii) do so in a way that makes its proper functioning evident. In other words, regulation should guide and constrain economic activity in such a way that the raison d'être of a market is broadly fulfilled, and can be seen to be fulfilled. Then a market will have achieved legitimacy.

\section{A Place for rhetoric}

Achieving legitimacy requires not only well-calibrated regulation, but also well-crafted rhetoric, so that it is seen as functioning properly by those who are involved. The recognition aspect is essential for a realization of the raison d'être that is secure and sustainable over time. The practice will continue only if it is endorsed by participants as serving the values that justify its continued existence. This means that the case for a market must be made to participants in 
such a way that a wide cross-section of them recognize that it is fulfilling its potential. In other words, the participants who recognize it must significantly outnumber those who do not, and those who do must include members of multiple socioeconomic categories - the poor and the wealthy in all cases, and in some circumstances subgroups corresponding to gender, race, language, and so forth. Hence, those who are in charge must "sell the public" on the market's promise, as well as show that it has been fulfilled.

This is easier than it sounds because the basic ideas are intuitive and graspable. Former U.S. President Barack Obama engaged in this public rhetoric in his 2016 op-ed in The Economist, which expanded on his speech to the United Nations. There he enumerates a plurality of ways that markets can fall short of what we expect:

Some of the [recent] discontent is rooted in legitimate concerns about long-term economic forces. Decades of declining productivity growth and rising inequality have resulted in slower income growth for low- and middle-income families. Globalisation and automation have weakened the position of workers and their ability to secure a decent wage. Too many potential physicists and engineers spend their careers shifting money around in the financial sector, instead of applying their talents to innovating in the real economy. And the financial crisis of 2008 only seemed to increase the isolation of corporations and elites, who often seem to live by a different set of rules to ordinary citizens. So it's no wonder that so many are receptive to the argument that the game is rigged. But amid this understandable frustration, much of it fanned by politicians who would actually make the problem worse rather than better, it is important to remember 
that capitalism has been the greatest driver of prosperity and opportunity the world has ever known. ${ }^{59}$

Obama explicitly names prosperity and opportunity as two key values that markets enable. But implicit in his list of "legitimate concerns" are other goods that markets should not ignore entirely: broad-based income growth, sufficient wages to meet one's needs, a price mechanism in financial services that better reflects genuine contribution, and avoiding the concentration of power among elites. Having validated the perception that markets are not functioning properly, he then goes deeper into why his audience should not lose faith in markets:

The profit motive can be a powerful force for the common good, driving businesses to create products that consumers rave about or motivating banks to lend to growing businesses. But, by itself, this will not lead to broadly shared prosperity and growth. Economists have long recognized that markets, left to their own devices, can fail. This can happen through the tendency towards monopoly and rent-seeking, the failure of businesses to take into account the impact of their decisions on others, the ways in which disparities of information can leave consumers vulnerable to dangerous products ... More fundamentally, a capitalism shaped by the few and unaccountable to the many is a threat to all. Economies are more successful when we close the gap between rich and poor and growth is broadly based. A world in which $1 \%$ of humanity controls as much wealth as the other $99 \%$ will never be stable. ${ }^{60}$

Thus he acknowledges that markets can be seen as worthwhile only if these problems are addressed. Otherwise, markets fail in their core value proposition, even if they deliver other

\footnotetext{
${ }^{59}$ Barack Obama, "The Way Ahead," The Economist, October 8, 2016.

${ }^{60}$ Ibid.
} 
benefits. While reminding us that America's economy is "enormously complicated," Obama nevertheless points to how these problems could be addressed jointly. He emphasizes that we should contrive particular policy adjustments that allow us to advance one aim of markets without undercutting others. For instance, "Curbs to entitlement growth that build on the Affordable Care Act's progress in reducing health-care costs and limiting tax breaks for the most fortunate can address long-term fiscal challenges without sacrificing investments in growth and opportunity." Whether or not this is true, it illustrates the sort of balancing judgment that I described earlier-how to promote one good without entirely sacrificing others. Overall, Obama's speech conveys to a general audience that economic regulation consists of delicately balancing a set of vital goods. Since this balancing is something that ordinary people can understand — just like the menu at a large feast—no mystification is required. ${ }^{61}$ While the overall argument will not be won or lost in a single speech, Obama's rhetoric cuts through the political propaganda (on both sides) and provides an example of how to sell a disillusioned public on the promise of the market.

\section{Comparative advantages}

Adopting this standard for market legitimacy allows us to jettison several problematic aspects of other accounts. First, it allows us to assess markets on multiple evaluative dimensions rather than just one. For example, we need not make the dubious claim that markets are legitimate because they maximize utility. Also, we need not rely exclusively on moral ideals of self-ownership or natural property rights as the basis of market legitimacy. Furthermore, it allows us to avoid the simplistic dichotomy of freedom and coercion. Markets are not always

${ }^{61}$ Seeking to persuade people that markets serve a plurality of goods reduces the authority of economic experts, rightly in my view. It thereby avoids condescending presumptions by elites that the masses fail to understand how good markets are for them. 
free of coercion, and this is one reason that I replaced the typical slogan of "cooperation without coercion" with "cooperation without collectivism." ${ }^{62}$ This account offers a standard of market legitimacy in which we do not need to rely on abstract idealizations of freedom and equality. ${ }^{63}$ Avoiding over-reliance on these one-dimensional standards of market legitimacy is a major advantage.

A further advantage is that this legitimacy standard broadens the horizons of those who regulate markets. They can sidestep the pressure to justify all of their regulation in the narrow terms of market failure as defined by economists. This account also makes a place for rhetoric in securing the endorsement of participants in a market, rather than relying on forms of justification that are accessible only to experts. Overall, this account of market legitimacy provides a more comprehensive and coherent basis for criticizing and reforming markets.

Finally, this standard allows us to say that while markets can be valuable in certain circumstances, they are not the solution to every social problem. The degree to which market institutions deliver the goods that would justify their existence varies according to the particular item that is being exchanged — consider, for instance, markets in votes. It also varies according to the context and background conditions. There are some circumstances in which markets simply cannot function properly, and this is not just a matter of fine-tuning the regulation. In these situations, market arrangements would set back important human interests, because the conditions are not suitable. Markets are not intrinsically legitimate, whenever and wherever they exist. Instead, they are capable of being legitimate, depending on the circumstances.

\footnotetext{
${ }^{62}$ For an argument that bargaining in labor markets can involve coercion, or at least a problematic "bending your action away from the reasons that govern it," see A. J. Julius, "The Possibility of Exchange," Politics, Philosophy and Economics 12, no. 4 [2013]: 370-72).

${ }^{63}$ I would argue that the more unattainable the value grounding legitimacy is, the more it is liable to political exploitation. See Amanda R. Greene, "Democratic Legitimacy for Skeptics," unpublished manuscript.
} 


\section{CONCLUSION}

I began the essay by accepting the intuition that whatever we take market legitimacy to mean, it must be distinct from justice and legality. This led me to ask: How do the interests and values served by markets provide a basis for its legitimacy? I proposed to answer this in terms of the market's promise - a potential to be valuable that, if fulfilled, would justify its existence. When markets fulfil their promise, and do so in a way that is recognized by participants, then they are legitimate. I argued that the distinctive promise of a market - its raison d'être - is to facilitate cooperation on a large scale, without the need for individuals to have shared ends, deliberation about ends, or even shared views about justice. This understanding of markets finds support, I suggested, in Aristotle's answer to a puzzle—namely, why a system of trade for mutual advantage does not amount to a political community. The benefits of market-based cooperation, I argued, are not merely individual discretion and esteem; they also include broader social goods such as wealth, diffusion of power, and freedom of association. Therefore, I argued, cooperation without collectivism represents the raison d'être of markets. When a market delivers and is widely seen as delivering on its promise, I argued, then it is legitimate.

I also began the essay by highlighting what we stand to gain by having an account of market legitimacy. For one thing, clarity about the nature of market legitimacy enables us to better evaluate markets by disentangling various grounds of criticism. The account that I defend shows us that utility, autonomy, and self-ownership all have their place in the story, though each is only part of the story. Once we separate out the various values that markets can serve, and make explicit that they can come into tension, we are in a better position to make targeted improvements in their realization. This account, therefore, furnishes regulators with a job description - that is, something to aim at as they draw the boundaries of legal protection of 
economic activity. Since the promise of a market is to deliver a plurality of goods, none of these goods can be entirely neglected by regulators. At the same time, the aim of balancing multiple goods provides regulators with some guidance in devising appropriate interventions. When regulators' understanding of market failure is appropriately nuanced, as my account allows, then economic regulation can be suitably calibrated to serve the deeper human interests at stake in market relations.

Finally, I began the essay by lamenting the mistrust that plagues our public discourse on markets. At the moment, political debates about economic rights are highly polarized. One tribe invokes the authority of educated experts, while another tribe exploits popular doubts about elite expertise. The account of market legitimacy that I defend is especially well-suited to address this problem because of its emphasis on widespread recognition by participants. On my account, market legitimacy rests not only on the fulfilment of a raison d'être, but the recognition of that fulfilment. I argued that this recognition is morally significant: Not only is it better for individual participants in a practice to be non-alienated, it also matters for the group that there is widespread acknowledgement of the practice as valuable. This mode of engagement is vital if a practice is to be sustained on grounds other than coercion or manipulation. And so insofar as a particular practice is valuable, I suggested, recognition of that fact by participants is valuable. The recognitional aspect of legitimacy also shows us, I argued, the importance of rhetoric. As I illustrated with a presidential speech after a crisis, rhetoric can dissolve the mystique of markets and economic experts. When rhetoric is used effectively, it helps to forge and foster a shared sense of the values that markets serve. And so it becomes clearer to everyone why not all markets are legitimate, even though some are. 